DOI: $10.20472 / T E .2018 .6 .2 .002$

\title{
APPLYING STUDENT EVALUATION OF TEACHING (SET) IN VIRTUAL LEARNING ENVIRONMENT (CASE STUDY: SYRIAN VIRTUAL LEARNING)
}

\author{
KHALIL AJAMI, OLA HAIDAR
}

\begin{abstract}
:
The evaluation of tutors using Student Evaluation of Teaching (SET) is an important Mechanism for quality assessment of teaching either in traditional learning or in virtual learning. However, the main question that could be raised here: Is there any difference in student evaluation of teaching (which is done by means of well-organized questionnaires) between traditional and virtual environments? In this paper, we apply SET within virtual learning environment. This is performed by modifying and introducing new factors to a standard SET evaluation questionnaire used in traditional environment, in order to transform it to a new one compatible with virtual environment. Our aim is to prove, using an empirical methodology, the validity of the new SET evaluation questionnaire within virtual learning.

Our results prove that many traditional factors such as: number of attendees, tutor gender, tutor age, tutor specialty, have no effect on students' evaluation in virtual learning environment, while new introduced factors such as: course success rate, learning management system organization, well organized on-line sessions, interactivity during on-line sessions, tutor's commitment, responding to students' questions out of the online sessions by mail or social media...etc. affect SET positively.
\end{abstract}

\section{Keywords:}

Student evaluation of teaching - Virtual learning - SVU - SET factors - interactivity - learning management system organization - Student - Class - Session - Course

JEL Classification: 129

\section{Authors:}

KHALIL AJAMI, Syrian Virtual University, Syrian Arab Republic, Email: ajami.khalil@gmail.com OLA HAIDAR, Syrian Virtual University, Syrian Arab Republic, Email: ola.haidar@gmail.com

\section{Citation:}

KHALIL AJAMI, OLA HAIDAR (2018). Applying Student Evaluation of Teaching (SET) in virtual learning environment (Case Study: Syrian Virtual Learning). International Journal of Teaching and Education, Vol. VI(2), pp. 24-45., 10.20472/TE.2018.6.2.002 


\section{INTRODUCTION}

Teaching, like all other professions, has to be continuously evaluated and improved by gathering all needed information that measure affecting factors influences. Teaching evaluation is a necessity in every learning environment, and it's the essence of quality control. However, teaching evaluation includes several axes such as course content, instructor support, course structure, instructor-student interaction, and student-student interaction ...etc.

In this paper, we present a methodology for teaching evaluation where student's feedback is a valuable source of information that teacher and university can use to improve their quality. This process is called student evaluation of teaching (SET) which is performed at the end of each semester in order to identify weakness and strength of learning environment and to help teachers to identify problems in their teaching and provide ways to tackle them. It is used widely as a primary indicator of teaching effectiveness of college and university instructors in the process of promotion and annual reviews.

However, In virtual learning, which is a type of learning that has the following six components: (1) synchronous sessions, (2) asynchronous sessions, (3) content, (4) exams, (5) assignments, (6) viva; and where e-learning and telecommunications technology play major role in teaching operation, tutor evaluation is not less important comparing with traditional learning environment. Thus, SET is needed in virtual learning in order to get student feedback about their tutors.

However, in virtual learning environment like the SVU, where e-learning and telecommunications technology play major role in teaching operation presented by the following six components: (1) synchronous sessions, (2) asynchronous sessions, (3) content, (4) exams, (5) assignments and (6) viva. Thus tutor evaluation in a SET form is not less important comparing with traditional learning environment and is needed in virtual learning in order to get student feedback about their tutors.

Therefore, a customization of a standard SET questionnaire is needed in order to adapt it to virtual learning environment nature. The new questionnaires should reflect the satisfaction of students towards their interaction with tutors virtually, and should reflect how much these factors affect the evaluation of tutors.

In order to present our methodology and our results, we organize this article as follows: Chapter 2 points out to the state of the art concerning teaching evaluation, and specially student evaluation of teaching (SET). This is presented in 2 sections: the first (2.1) is related to general studies clarified the factors that affect SET, either in traditional learning or in virtual learning. While the second (2.2) presents SET questionnaire used in Stanford University in a traditional learning environment. Chapter 3 presents SET application at Syrian Virtual University (SVU) as a case study: the first section of chapter 3 (section 3.1) presents factors that affect virtual learning evaluation and the hypothesis that we will examine after analyzing questionnaire results. The second section (3.2) presents the new questionnaire used in SVU. Conclusion about what we have done in the paper comes later with results of analyzing the questionnaire outcome. And at the end, we presented a perspective about what we will do in the future regarding quality assurance process at SVU. 


\section{2- STATE OF THE ART}

\subsection{General}

James E. Miller from Harding University wrote: "The question driving some multi-section course studies is, "Do instructors who receive high ratings from students actually teach their students more effectively so that they perform better on the common final exam?" and he mentioned many previous studies that assures this idea like Murray (2005); Aleamoni\&Hexner, 1980; Centra, 1977; Cohen, 1981; McKeachie, 1990) (Miller, 2007). However, there is a problem related to SET credibility, whereas instructors who give higherthan-deserved grades generally will be rewarded with higher-than-deserved SETs. (Eduardo \& al 2011) (Herbert \& al 1997) (Eduardo \& al 2011) (STANFORD UNIVERSITY NEWSLETTER ON TEACHING 1997)

In fact, many studies examine factors that affect SET and though affect the whole process of learning evaluation. Some factors affect SET in both traditional and virtual learning, others don't. We present in the following the main factors:

- Class size:

One of these studied factors is class size, or the number of students enrolled in class at the beginning of the semester in a classroom-based teaching. It was realized that it affects negatively the SET score as the greater the number of students in class, the less amount of personal communication or attention that a teacher can give to any particular student and the lower is the SET grade (Eduardo \& al 2011) (Verena 2011) (Palmer 2011). Other research studies examining the impact of class size on student evaluation showed mixed results. In small classes, students have more interaction with their instructors, besides their ability to do more critical thinking activities with them. On the other hand, in big classes, tutors efficiency come out in dealing with more students, and that motivates them to teach effectively (Lui Ou 2012).

In a distance education system, the impact of class size is less important, it's different from findings reported in previous studies. Class size in general does not significantly impact student ratings (Lui Ou 2012)..

While class size impact on traditional courses effectiveness was studied in many researches, few only were done for online courses. It was proved after making a survey on 1126 MBA students from both conventional and online courses, that in traditional courses the relation between class size and teaching effectiveness is negative, on the contrary in online courses, it has no relation. (Palmer 2011) (Drago \& al 2004)

- Tutor experience:

Moreover, instructors with more experience are better evaluated, since experience in the classroom tends to increase teaching quality. The longer the instructors experience teaching the greater is their evaluations. (Eduardo \& al 2011) (Herbert \& al 1997) - Instructor age:

The instructor's age and schooling do not affect the way students evaluate him. (Eduardo \& al 2011)

-Expected grades:

A number of researchers have found a positive relationship between students expected grades and SET ratings. Intuitively, a student earning high grade in a course tends to be 
more satisfied with the instructor than one earning failing grade. (Eduardo \& al 2011) (Herbert \& AL 1997) (Clifford \& al 2010)

\section{- Gender:}

Some studies show that there is no indication that male and female students have different standards when evaluating instructors, also no difference in perception with respect to the instructor's gender by the students (Eduardo \& al 2011). While others have found that female students on average tend to give significantly higher SET ratings than their male peers (Bachen \& al 1999) (Badri \& al 2006) (Pounder 2007). This result was replicated in other study, although the effect was small (Verena 2011). Thus we can confirm that females gave -generally- higher ratings than males in traditional learning, however the effect of gender is non-significant in online education. The lack of effect may be related to the unique feature of online education that there is no or very limited face-to-face interaction between the instructor and the students (Lui Ou 2012).

- Student year level:

A commonly observed positive association between year level and SET ratings also existed, it's related to student maturity (Lui Ou 2012) (Pounder 2007).

\subsection{The evaluation process at Stanford University:}

In this section, we explore the way that Stanford University, which is one of the world's most prestigious institutions, uses to evaluate courses by taking students opinions about their semester courses.

In Stanford, as in most colleges and universities, student ratings of courses are important for many reasons. It helps departments and top management to make decisions about promotion, retention, tenure, but the most important benefit is the feedback to instructors that help them improve their teaching practices to provide students with better learning experiences (STANFORD UNIVERSITY NEWSLETTER ON TEACHING 1997). The use of such evaluation is important as an evaluation reference in a traditional learning environment. It helps to highlight the difference of evaluation methods between traditional learning and virtual learning.

Stanford evaluation questionnaire consists of the following points:

1. Overall Ratings

1.1 Instructor's overall teaching

1.2 The quality of the course content

2. Instructor's Organization/Clarity

2.1 Set out and met clear objectives announced for the course

2.2 Displayed thorough knowledge of course material

2.3 Explained concepts clearly

2.4 Distinguished between more important and less important topics

2.5 Presented material at an appropriate pace

3. Instructor's Ability to Engage and Challenge Students Intellectually

3.1 Emphasized conceptual understanding and/or critical thinking

3.2 Related course topics to one another

4. Instructor's Interaction with Students 
4.1 Demonstrated concern about whether students were learning

4.2 Inspired and motivated student interest in the course content

4.3Was available for consultation outside of class

5. Course Organization, Content, and Evaluation

5.1 Selected course content that was valuable and worth learning

5.2Organized course topics in a coherent fashion

5.3 Chose assignments that solidified understanding

5.4 Explained clearly how students would be evaluated

5.5Designed and used fair grading procedures

6. Section/Lab Integration

6.1 Section or lab was well integrated into course structure

6.2What we are concerned of are the points related to instructor's evaluation.

\section{3- SVU SET}

Syrian Virtual University (SVU) is a public academic institution established in 2002 in response to developments in e-learning. SVU is the first virtual education institution in the region. Its objective is to develop human resources in various disciplines in order to meet the needs of economic and social developments and market needs and to keep abreast with the requirements of a knowledge-based economy, especially in areas like Information and Management Systems, E-Marketing, IT and Internet Technologies. SVU is constantly developing its infrastructure and expanding its centers to accommodate the rapid increase in demand on its services, since the number of SVU students actually reached 30 thousand students

In our work, we use (SVU) as a case study representing full virtual learning environment with the six learning components mentioned in our introduction. Main systems used in it are:

- SVU Student Information System (SVUIS) which gives the student the ability of registration - choosing courses and classes - previewing his studying profile.

- Learning Management System (LMS/Moodle) which enables the student to take his courses' content and applying his assignments.

- Virtual Classroom System (Webdemo/Linktivity Player) the system of online sessions.

- SVU Assessment Management System (EXams) the exams system... etc.

There is no clear evaluation method at SVU that provides feedback of the course effectiveness, student satisfaction...etc. Therefore, it's a necessity to apply a complete process of course evaluation including student evaluation of tutors which includes his performance in all used systems at the university that are previously mentioned.

We studied factors that affect virtual learning in SVU, besides using Stanford SET questionnaire as a reference and changed it to be convenient with virtual learning environment, and added few questions according to that.

Our sample consists of fall 2015 (F15) students' semester and the reasons were: obtaining maximum number of responses, and having comprehensive sample that is not restricted to specific program or studying year. 
The survey was sent at the end of the term's teaching period to guarantee the credibility of students' answers before exams and final results.

39380 requests were sent and 4903 responses were received, each one represents an evaluation for a tutor in a specific course. SET calculation in a statistical and data-analyzing context is the "Mean frequency" of the students answers to the survey factors, which can be calculated for each factor (set.factor) by the formula:

$$
\text { set.factor }=\frac{\sum_{i=1}^{5}(f i * x i)}{\sum_{i=1}^{S} f i}
$$

$x:$ is a range from 1 to 5 (evaluation scale).

$f:$ is the frequency of each $x$ value in the factor values.

Denominator: is the sum of the frequencies of each $x$ values, in this case it will be the sample size (s).

After that, the tutor SET is calculated as the average value of the (set.factor) for all factors.

Finally, we analyzed the survey results and tested our hypothesis as explained in details in the following section (3.1).

\subsection{Factors affecting virtual learning evaluation in SVU (hypothesis) regarding to our state of the art presented in chapter 2}

In the following hypothesis, we mean by $\mathrm{HO}$ the null hypothesis (i.e. there is no relation between the two studied factors), while $\mathrm{H} 1$ refers to alternative hypothesis (i.e. there is a relation between the two studied factors).

Generally, a tutor could supervise multiple courses. Thus, students registered in a given course could evaluate their tutor separately from students registered in another course supervised by the same tutor. Consequently, the set (tutor-course) represents a subset of the Cartesian product (tutor $X$ course) between the set of tutors and the set of courses.

Moreover, our methodology for measuring the influence of each factor is summarized as follows:

For each factor (class size for example), we fix a value (or interval of values) for such a factor. We compute the mean, the standard deviation, and the distribution of SET marks regarding to tutor-course for this given factor value (class size value for example). Consequently, a factor with no effect will give by its variations the same distribution of SET marks.

\section{Class size:}

In virtual learning, class size has no effect. Generally, class size is different from the number of attendees in class as not all students in class attend synchronous sessions. So it was replaced by the factor: "number of attendees in sessions" that should be related to 
tutor evaluation, so we suppose here that highly rated tutors has more attendees according to their reputation and efficiency.

Hypothesis:

$\mathrm{HO}_{1}$ : Tutor's number of attendees and score (SET) are independent H11: Tutor's number of attendees depends on their score (SET)

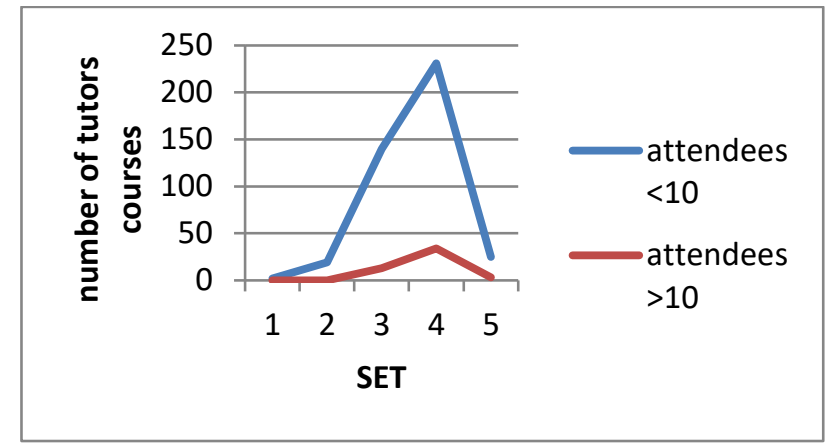

Fig (1-1) SET \& number of attendees

We divided tutors according to their number of attendees into two categories:

Tutors who have less than 10 students per session ( $<10$ students per session)

Tutors who have more than 10 students per session (>10 student per session)

Results:

From fig (1-1) we noticed that (1) most tutor-courses have SET value equal to 4. (2) It has also normal distribution with mean value equals to 4. (3) SET Distribution doesn't change when number of attendees change.

The result indicates also that evaluation has great credibility as it hasn't been affected by changes in number of attendees. This is normal because all sessions are recorded and there are a lot of factors that obstruct attending online sessions in Syria (related to war circumstances) besides student's commitment to their work.

In addition, Virtual learning doesn't depend completely on on-line or registered sessions, on the contrary, it depends more on student self-studying with the assistance of wellorganized content. Thus, we fail to reject $\mathrm{H} 01$.

Moreover, tutors with high evaluation in questions related to Moodle (i.e. learning management system used in SVU) have less attendees because students rely more on self-study where well-arranged Moodle help them more actively in their studies.

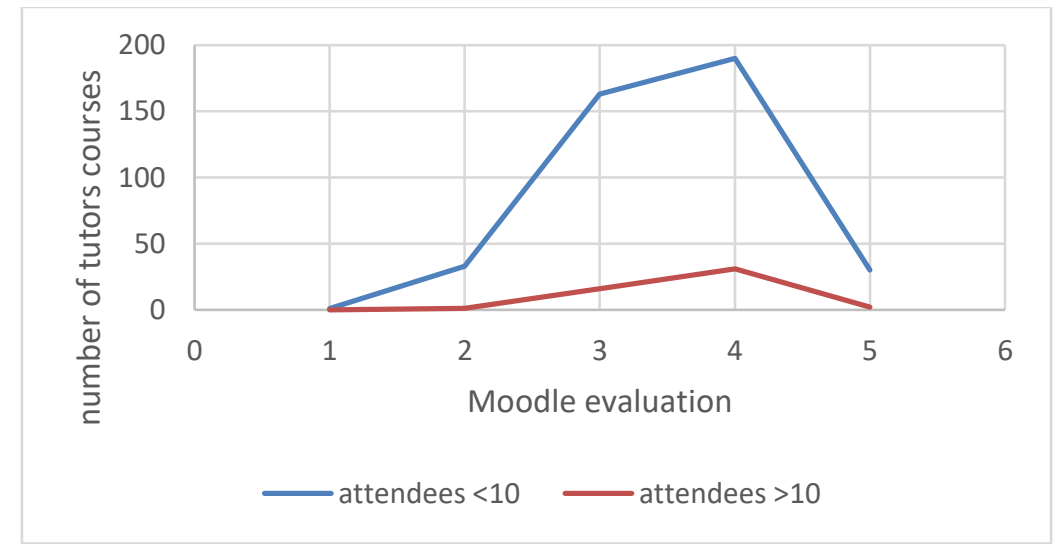


Fig (2-1) Moodle evaluation \& number of attendees

\section{Grades:}

Grades are related directly to tutor evaluation. Highly rated tutors have students with high grades, but at the same time, high grades affect negatively the reliability of tutor evaluation. SETs instructors who give higher than deserved grades will be rewarded with higher than deserved SETs. (Eduardo \& al 2011) (Herbert \& al 1997).

Hypothesis:

$\mathrm{HO}_{3}$ : Tutor's evaluation (SET) and students' grades are independent H13: Tutor's evaluation (SET) depends on students' grades

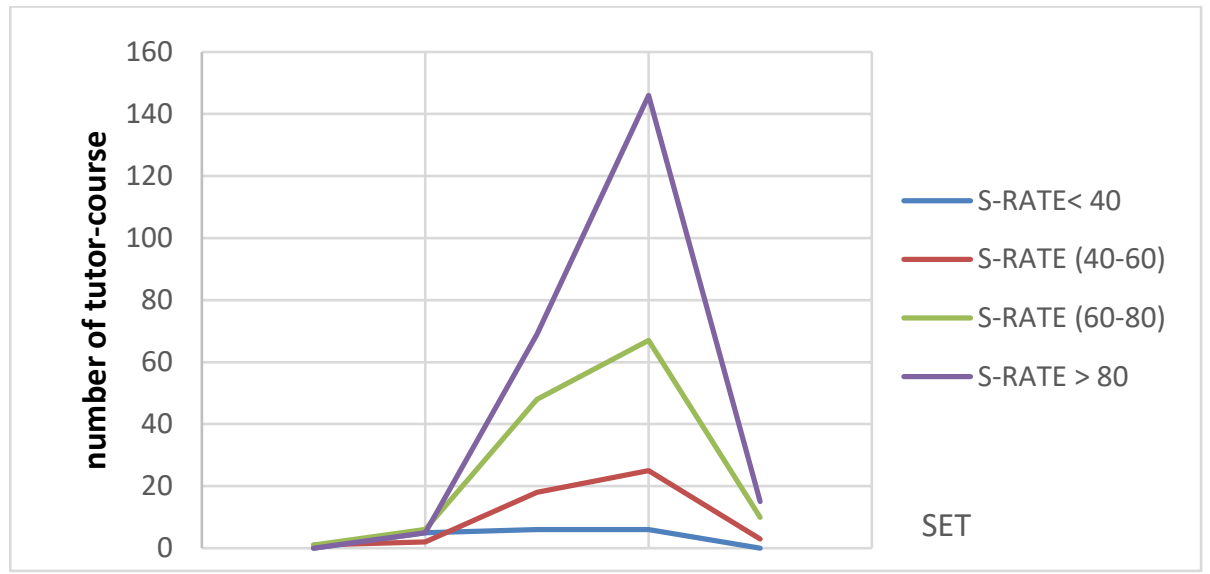

Fig (3-1) SET \& success rate

We divided students into:

Students with success rate less than 40 (S-RATE <40\%)

Students with success rate between 40 and 60 (S-RATE $40 \%-60 \%$ )

Students with success rate between 60 and 80 (S-RATE 60\%-80\%)

Students with success rate more than 80 (S-RATE > 80\%)

Results:

From fig (3-1), by neglecting marginal values $(1,5)$ since more than $90 \%$ of students give SET evaluation between 2 to 4 and concentrating on this sample we find that success rate is directly proportional with number of tutors courses who have high SET value (4) and we can reject $\mathrm{HO}_{3}$.

The factor that measures how much tutor's program is related to IT

Tutors' evaluation and the program they teach in, which reflect how much tutor's program is related to IT.

Hypothesis:

$\mathrm{H}_{4}$ : Tutor's evaluation (SET) and the factor that measures how much tutor's program is related to IT, are independent.

H14: Tutor's evaluation (SET) depends on the factor that measures how much tutor's program is related to IT. 
We divided tutor program into:

Programs related to IT (high)

Programs partially related to IT (med)

Programs not related to IT (low)

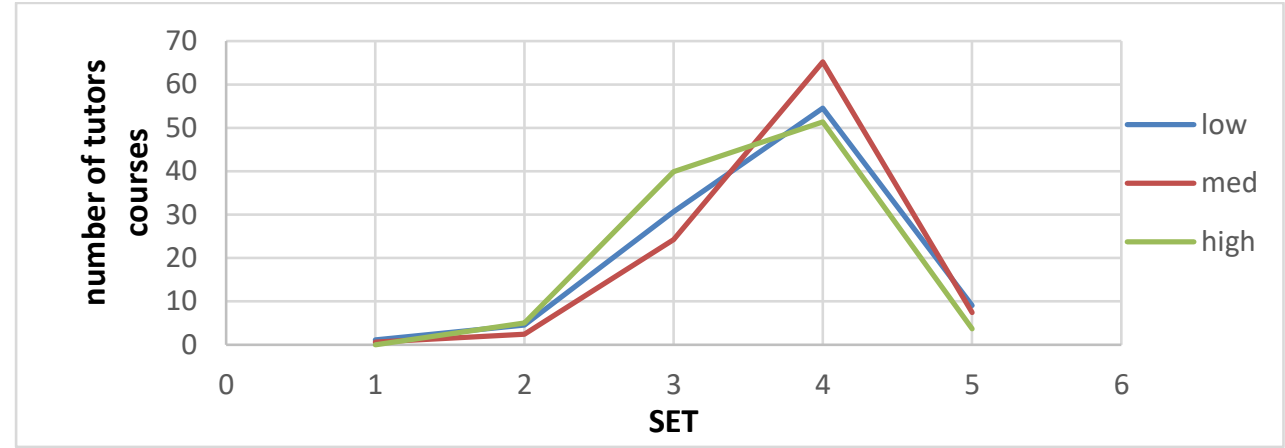

Fig (4-1) SET\&Program

Results:

From previous graph we can see that SET values don't vary between the three categories. So we fail to reject the null hypothesis. And that could be explained by the fact that some tutors strived extra efforts to be conformed to virtual learning even if they were not in the IT domain. On the other hand, if we look at the graph between tutor general evaluation and his/her evaluation in using virtual learning technologies we find that high general evaluations are associated to high technical evaluations.

\section{Tutor's age:}

There is no face-to-face interaction in virtual learning so instructor's age and gender do not affect the way students evaluate him. (Badri \& al 2006)

\section{Hypothesis:}

H05: Tutor's evaluation (SET) and tutor's age are independent.

H15: Tutor's evaluation (SET) is related to tutor's age.

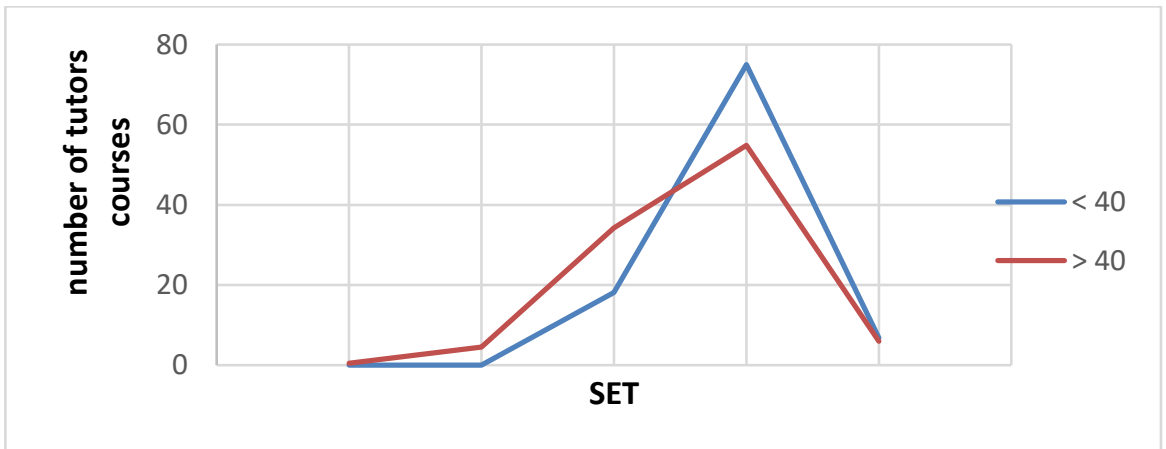

Fig (5-1) SET \& tutor age

Results: 
From fig (5-1) we fail to reject $\mathrm{HO5}$ as the two curves are almost identical, and there is no relation between tutor's age and his/her SET evaluation.

\section{Tutor's gender:}

Hypothesis:

H05: Tutor's evaluation (SET) and tutor gender are independent.

H15: Tutor's evaluation (SET) is related to tutor gender.

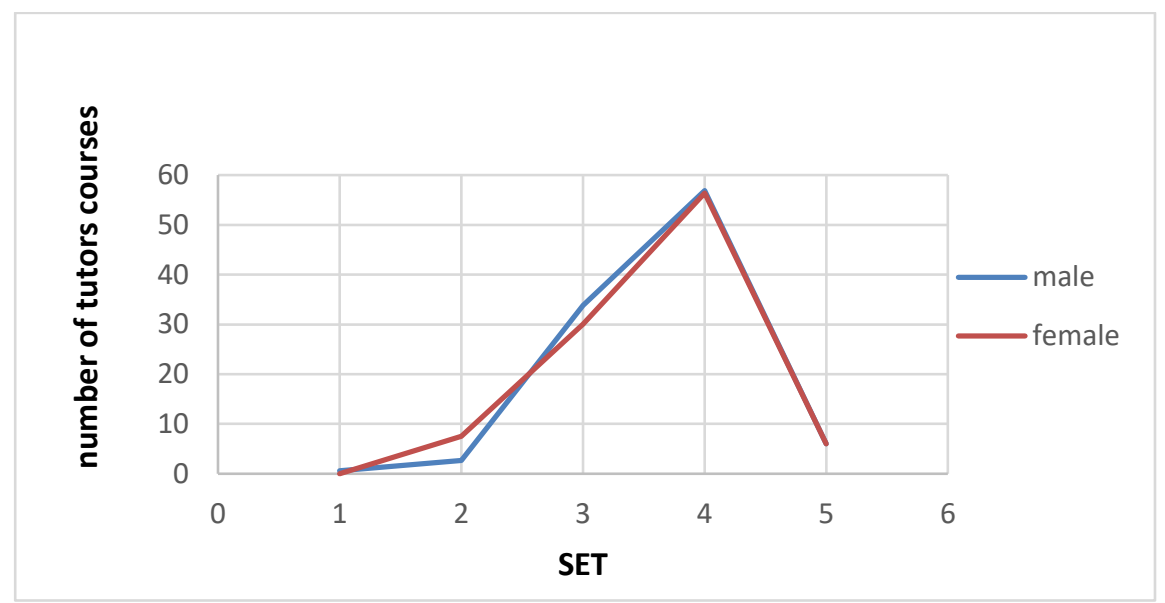

Fig (5-2) SET \& tutor gender

Results:

In fig (5-2), we fail to reject $\mathrm{HO5}$ as the two curves are almost identical and there is no relation between tutor's gender and his/her SET evaluation.

According to previous studies, female students on average tend to give significantly higher SET ratings than their male peers (Clifford \& al 2010). But that is not true in virtual evaluation according to the results we had.

\section{Tutor's evaluation in arranging used learning management system (Moodle):}

In a self-learning criteria like the one applied in SVU, tutor's arrangement to his/her course pages on LMS has a big importance in enhancing the learning process. Such as dividing the course into sections related to the course syllabus, presenting the assignment in a clear way, enrich the content with suitable extra materials ... etc.

Hypothesis:

H06: general evaluation of each tutor/course is independent from his/her evaluation in Moodle.

H16: general evaluation of each tutor/course depends on his/her evaluation in Moodle.

This is equivalent in Stanford evaluation questionnaire to 2.5 in chapter 2.2 


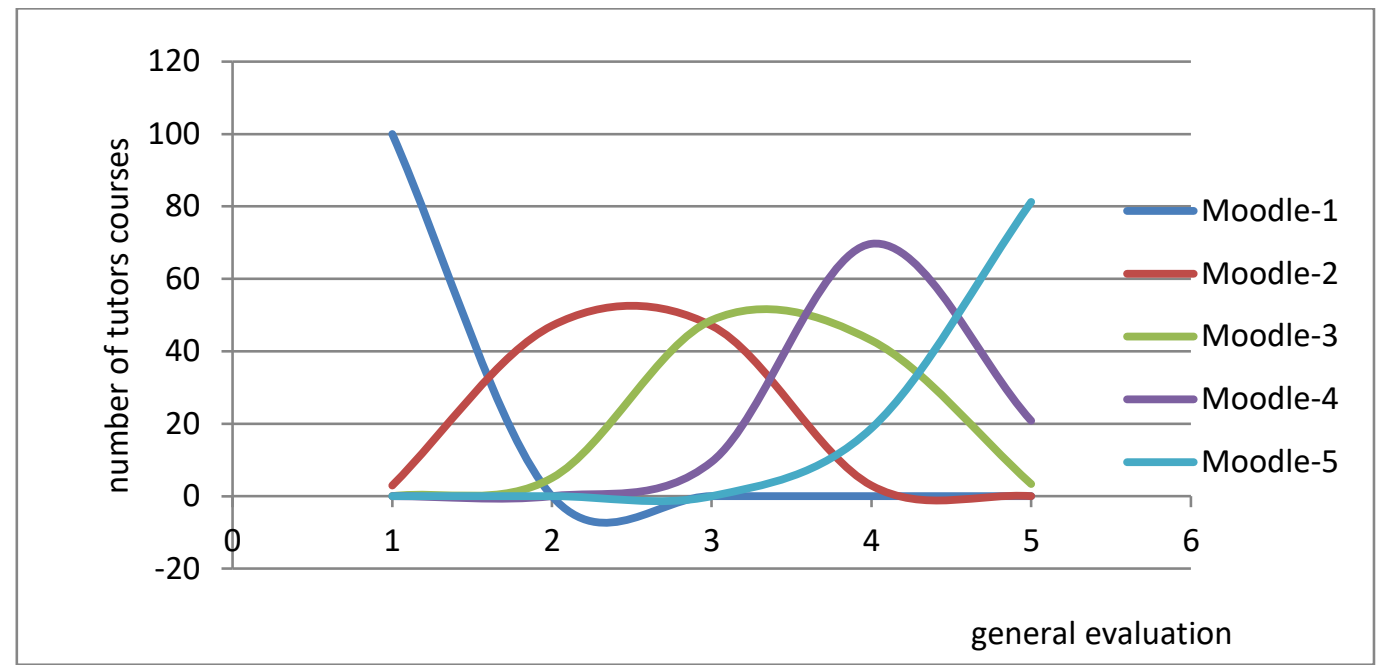

Fig (6-1) general evaluation\& Moodle evaluation

Results:

From Fig (6-1), since the biggest number of tutor-course has identical values of general evaluation and Moodle factor evaluation (the peak of Moodle-1 graph confronts a SET value equals 1, Moodle-2 graph confronts a SET value equals 2 and so on), we find that Moodle evaluation is directly proportional with general evaluation, so we can reject H06.

\section{Tutor's evaluation in declaring session objective clearly}

Hypothesis:

$\mathrm{H}_{7}$ : general evaluation of each tutor/course is independent from his/her evaluation in declaring session's goal.

H17: general evaluation of each tutor/course depends on his/her evaluation in declaring session's goal.

This is equivalent in Stanford evaluation questionnaire to 2.3 and 5.2 in chapter 2.2.

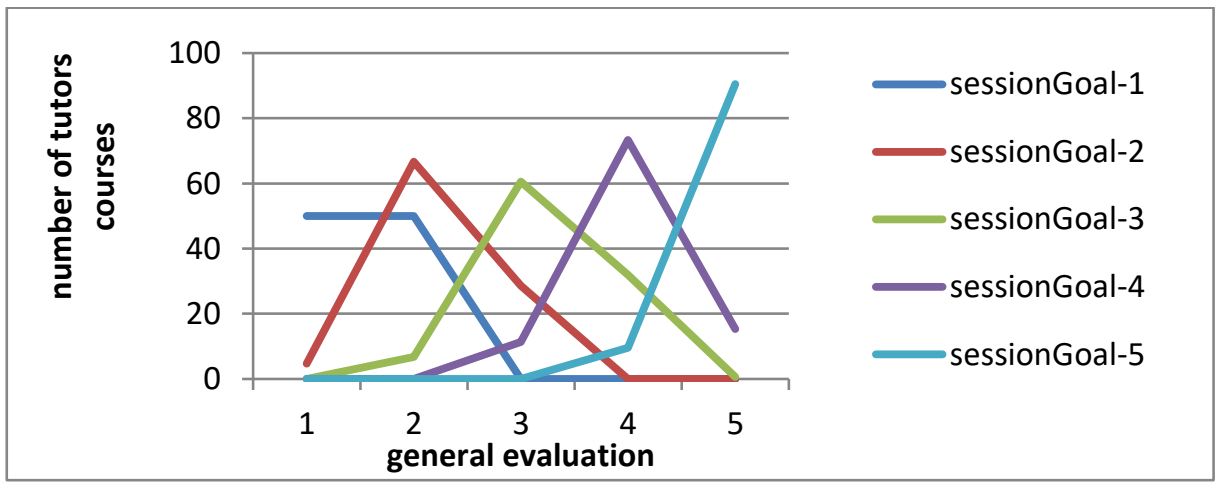

Fig (7-1) general evaluation \& session goal

Results:

From Fig(7-1) and with ignoring marginal values (1 and 5), since the peak value of the general evaluation equals declaring session's goal evaluation and the biggest number of 
tutor-course has identical values of general evaluation and session goal factor evaluation (the peak of sessionGoal-2 graph confronts a SET value equals 2, sessionGoal-3 graph confronts a SET value equals 3 and so on), we find that declaring session's goal evaluation is directly proportional with general evaluation so we can reject $\mathrm{H07}$.

\section{Tutor's Ideas and concepts were clear and related to each other}

Hypothesis:

$\mathrm{HO}_{8}$ : general evaluation of each tutor/course is independent from his/her evaluation in idea clearness.

H18: general evaluation of each tutor/course depends on his/her evaluation in idea clearness

This is equivalent in Stanford evaluation questionnaire to 2.1 and 3.2 in chapter 2.2.

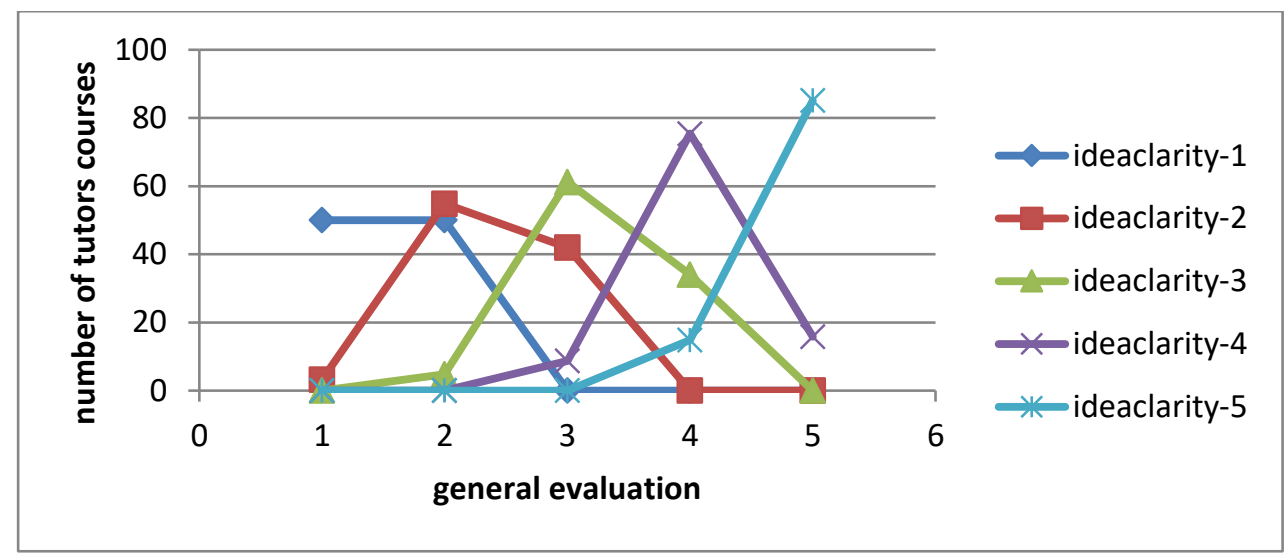

Fig (8-1) general evaluation \& idea clarity

Results:

With ignoring marginal values $(1,5)$, since the peak value of the general evaluation equals idea clarity evaluation and the biggest number of tutor-course has identical values of general evaluation and idea clarity factor evaluation (the peak of ideaclarity-2 graph confronts a SET value equals 2, ideaclarity-3 graph confronts a SET value equals 3 and so on), we find that idea clarity evaluation is directly proportional with general evaluation so we can reject $\mathrm{H} 08$.

\section{Sessions were supported with sufficient examples}

Hypothesis:

$\mathrm{HO}_{9}$ : general evaluation of each tutor/course is independent from his/her evaluation in using examples.

H19: general evaluation of each tutor/course depends on his/her evaluation in using examples.

This factor with all others related to interactivity during sessions are equivalent in Stanford evaluation questionnaire to 3.1 in chapter 2.2. 


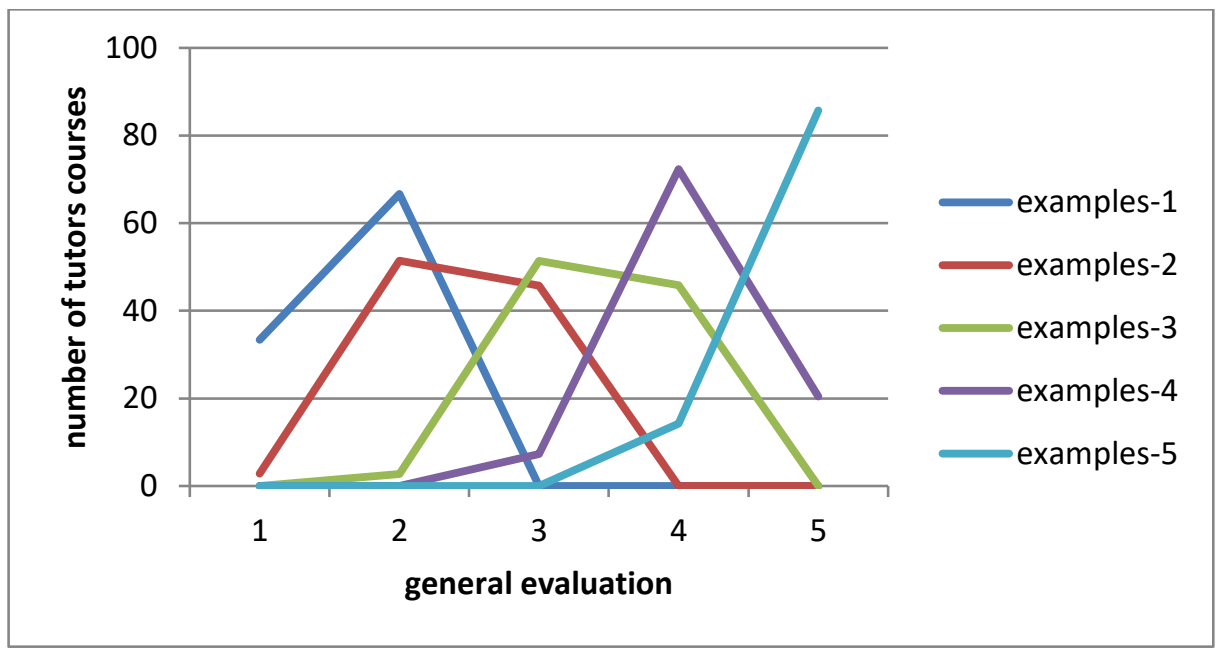

Fig (9-1) general evaluation \& using examples

Results:

With ignoring marginal values $(1,5)$, since the peak value of the general evaluation equals using examples evaluation and the biggest number of tutor-course has identical values of general evaluation and using examples factor evaluation (the peak of examples-2 graph confronts a SET value equals 2, examples- 3 graph confronts a SET value equals 3 and so on), we find that using examples evaluation is directly proportional with general evaluation so we can reject $\mathrm{H} 09$.

\section{Interactivity:}

Interactivity during sessions affects positively student evaluation of teaching. But many students in traditional learning prefer teaching that enables them to listen passively, teaching that organizes the subject matter for them and that prepares them well for tests (Alauddin, 2015).

Hypothesis:

$\mathrm{HO}_{10}$ : general evaluation of each tutor/course is independent from his/her evaluation in session interactivity.

$\mathrm{H} 1_{10}$ : general evaluation of each tutor/course depends on his/her evaluation in session interactivity. 


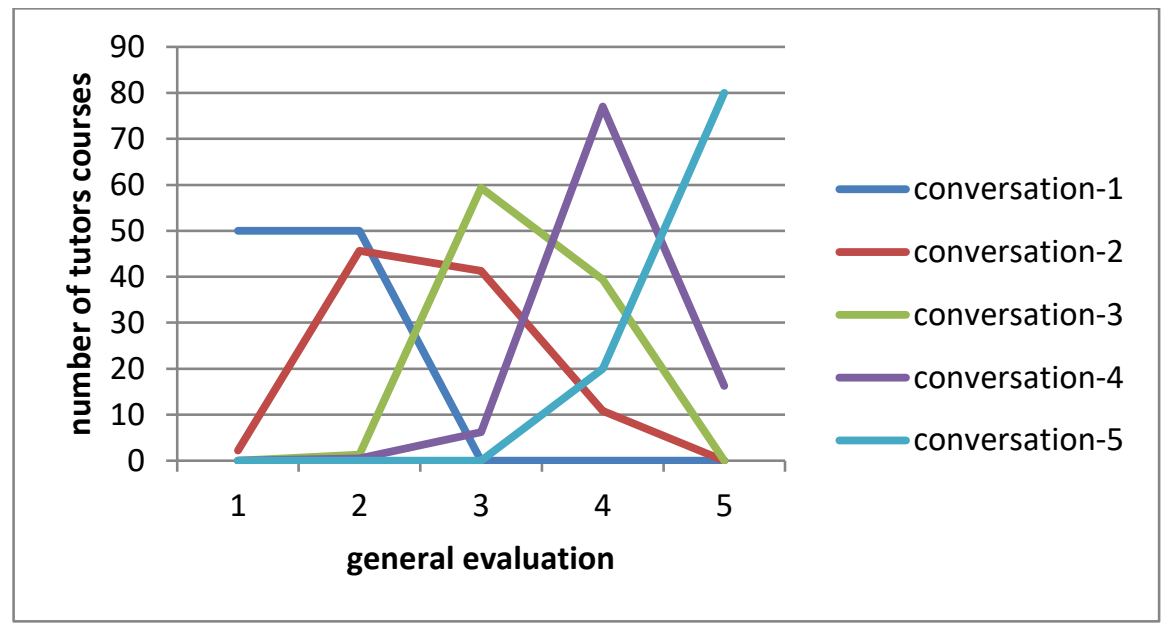

Fig (10-1) general evaluation \& session interactivity

Results:

With ignoring marginal values $(1,5)$, since the peak value of the general evaluation equals interactivity during sessions evaluation and the biggest number of tutor-course has identical values of general evaluation and conversation factor evaluation (the peak of conversation2 graph confronts a SET value equals 2, conversation-3 graph confronts a SET value equals 3 and so on), we find that tutors interactivity during sessions evaluation is directly proportional with general evaluation so we can reject $\mathrm{HO10}$.

\section{Response to students' questions was clear and sufficient}

Hypothesis:

$\mathrm{H} 0_{11}$ : general evaluation of each tutor/course is independent from his/her evaluation in session responding to questions.

$\mathrm{H} 1_{11}$ : general evaluation of each tutor/course depends on his/her evaluation in session responding to questions. 


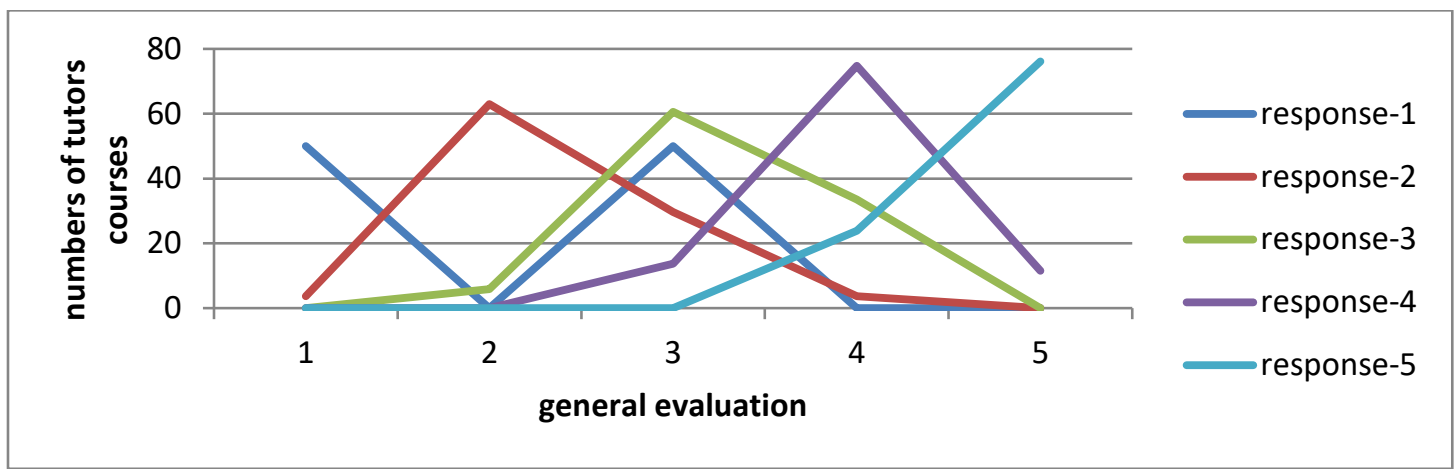

Fig (11-1) general evaluation \& responding to questions during sessions

Results:

With ignoring marginal values $(1,5)$, since the peak value of the general evaluation equals tutors responding during sessions evaluation and the biggest number of tutor-course has identical values of general evaluation and response factor evaluation (the peak of response-2 graph confronts a SET value equals 2, response-3 graph confronts a SET value equals 3 and so on), we find that tutors responding during sessions evaluation is directly proportional with general evaluation so we can reject H011. On the other hand, there is abnormality near the value 3 as some students evaluated their tutors with medium value while they were bad in responding.

\section{Response to students' questions outside sessions and in different ways (email- Moodle - social network - FB ...etc)}

Hypothesis:

$\mathrm{H} 0_{12}$ : general evaluation of each tutor/course is independent from his/her evaluation in responding to questions by social media.

H1 12: general evaluation of each tutor/course depends on his/her evaluation in responding to questions by social media.

This is equivalent in Stanford evaluation questionnaire to 4.3 in chapter 2.2.

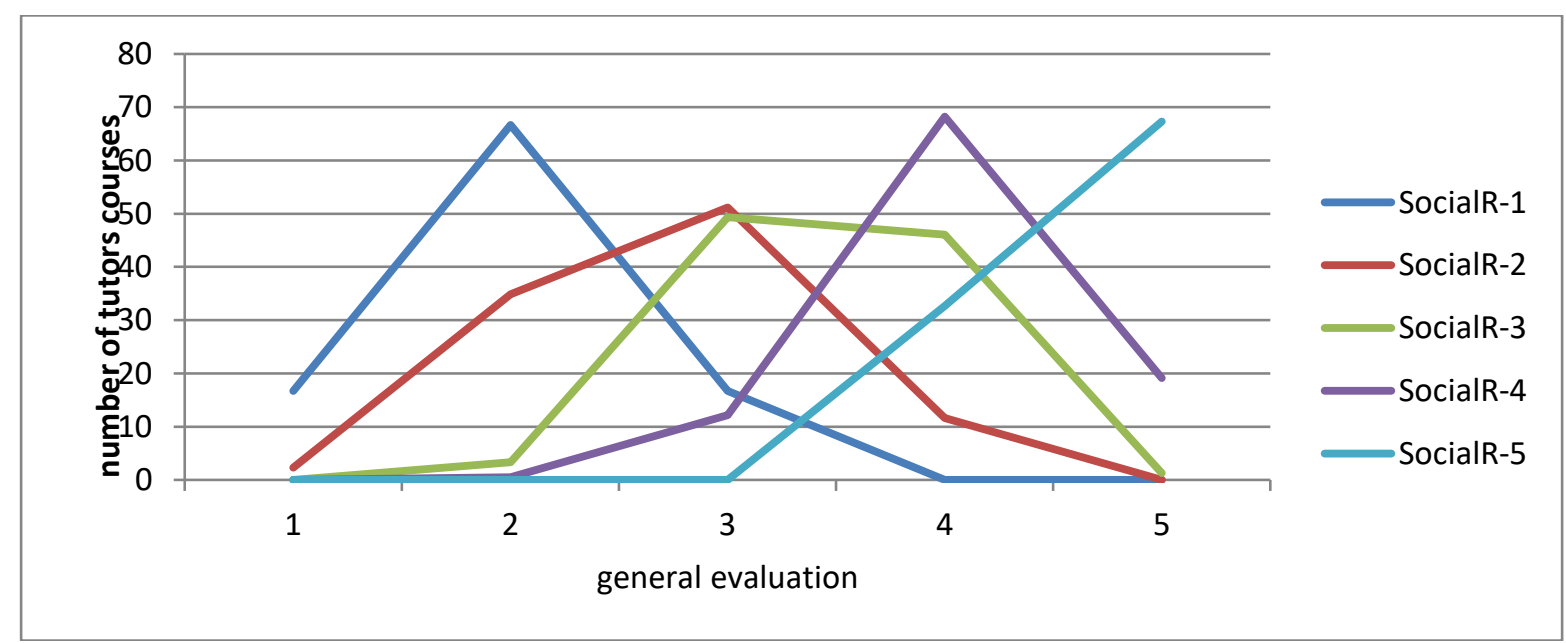

Fig (12-1) general evaluation \& responding by social media 
Results:

With ignoring marginal values $(1,5)$, since the peak value of the general evaluation equals responding to questions by other social media evaluation and the biggest number of tutorcourse has identical values of general evaluation and social response factor evaluation (the peak of SocialR-2 graph confronts a SET value equals 2, SocialR-3 graph confronts a SET value equals 3 and so on), we find that tutors responding to questions by other social media evaluation is directly proportional with general evaluation so we can reject $\mathrm{H} 012$. There is Abnormality near the value1; student gives two instead of one because it is not an essential way of communication.

\section{Commitment:}

Commitment in sessions timing, sessions recordings upload and announcements in case of session cancellations or changing time have a positive impact on tutor evaluation.

Hypothesis:

$\mathrm{H}_{13}$ : general evaluation of each tutor/course is independent from his/her evaluation in commitment in session timing.

$\mathrm{H} 1_{13}$ : general evaluation of each tutor/course depends on his/her evaluation in commitment in session timing.

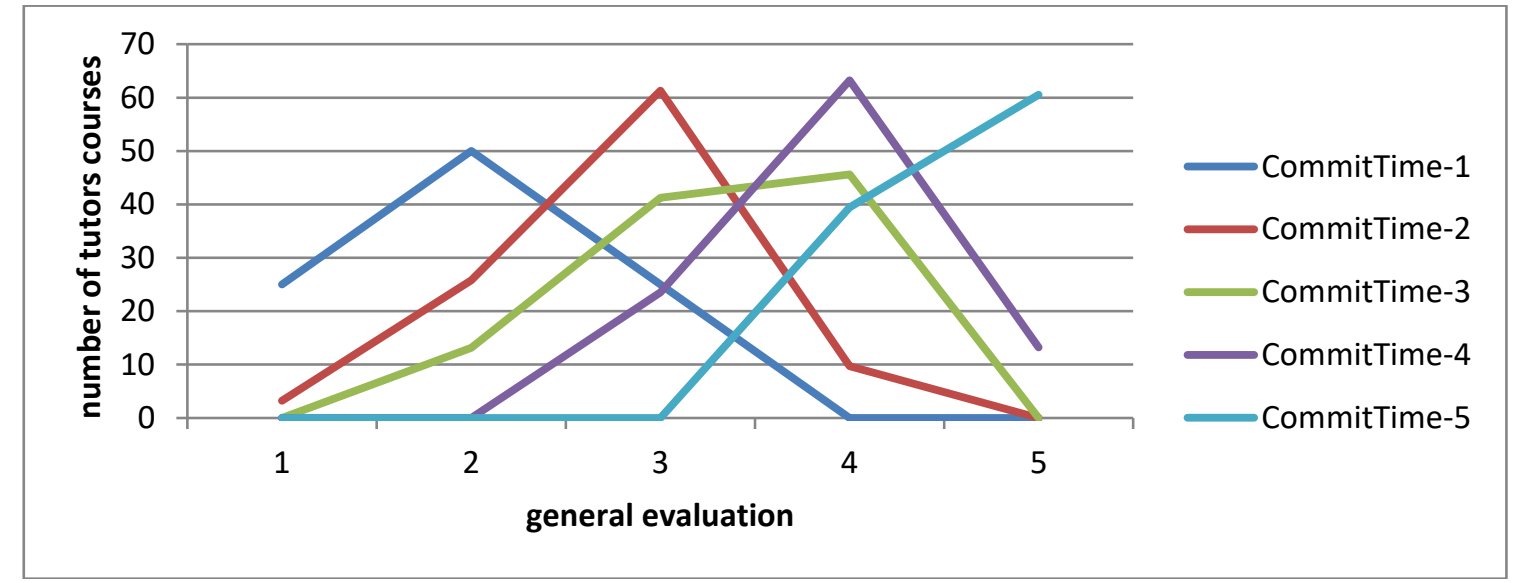

Fig (13-1) general evaluation \& commitment 1

Results:

With ignoring marginal values $(1,5)$, since the peak value of the general evaluation equals commitment in session timing evaluation and the biggest number of tutor-course has identical values of general evaluation and commitment time factor evaluation (the peak of CommitTime-2 graph confronts a SET value equals 2 CommitTime- 3 graph confronts a SET value equals 3 and so on), we find that tutors commitment in session timing evaluation is directly proportional with general evaluation so we can reject $\mathrm{H} 013$.

\section{Inform students in case of session cancellation}

Hypothesis:

$\mathrm{HO}$ 14: general evaluation of each tutor/course is independent from his/her evaluation in case of session cancellation. 
$\mathrm{H} 1_{14}$ general evaluation of each tutor/course depends on his/her evaluation in case of session cancellation.

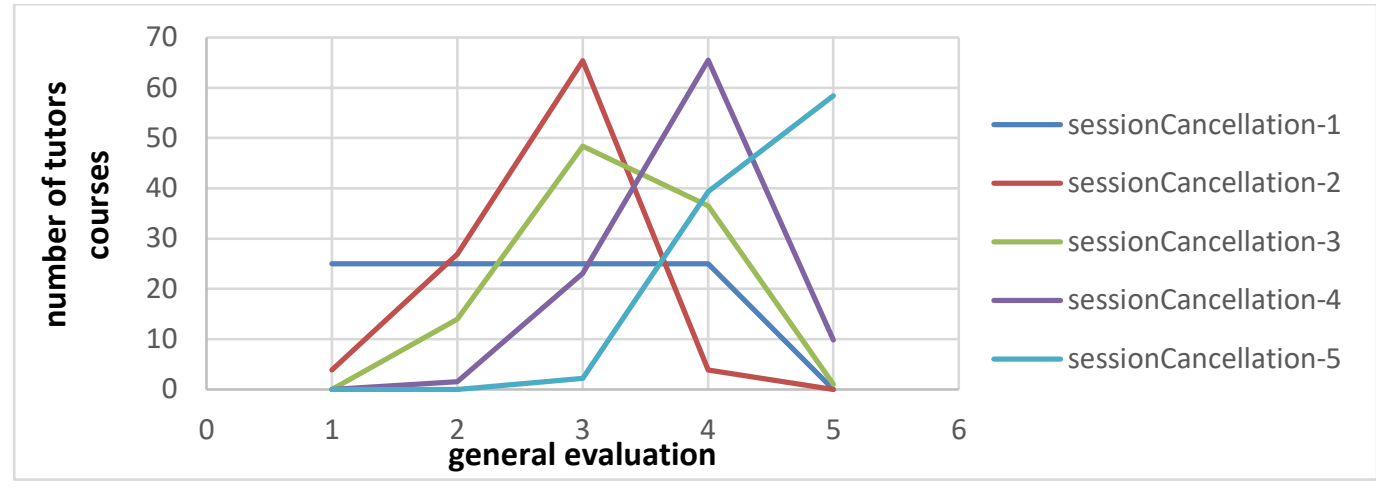

Fig (14-1) general evaluation \& session cancellation

Results:

From Fig (14-1) we find that there are no indications of relations between tutors' commitment in informing students in case of session cancellation evaluation and general evaluation, so we can't reject $\mathrm{H014}$ and we will exclude this question from future questionnaires.

\section{Sessions were uploaded on time without delay}

Hypothesis:

$\mathrm{HO}_{15}$ : general evaluation of each tutor/course is independent from his/her evaluation in session upload time.

H115: general evaluation of each tutor/course depends on his/her evaluation in session upload time.

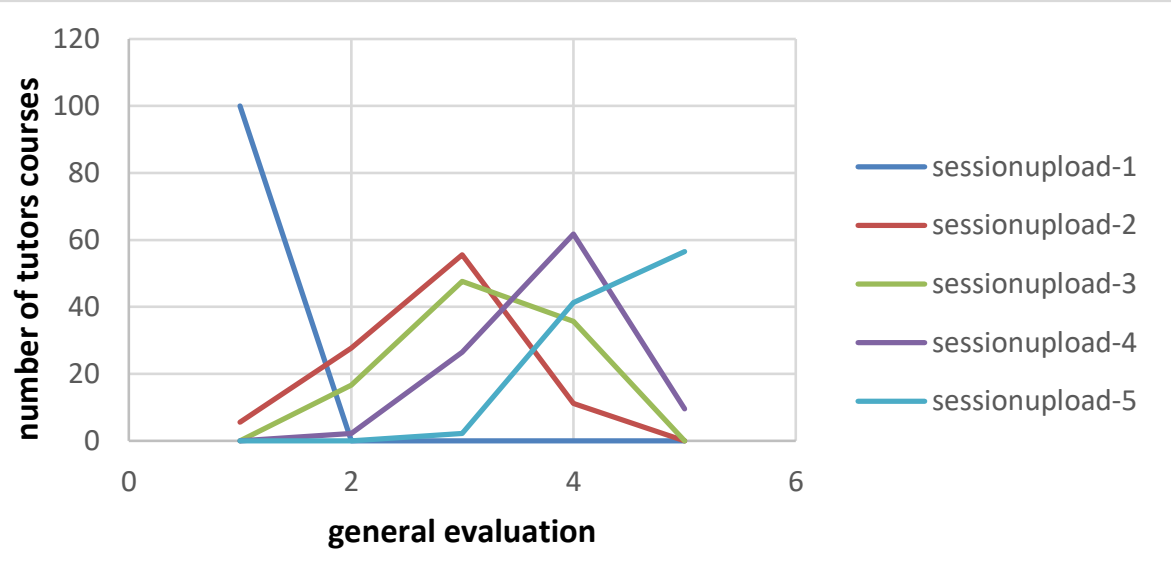

Fig (15-1) general evaluation \& session upload

Results:

With ignoring marginal values, since the peak value of the general evaluation equals commitment in session upload evaluation and the biggest number of tutor-course has identical values of general evaluation and session upload factor evaluation (in 
sessionupload-3 and sessionupload-4 graphs), we find that tutors commitment in session upload evaluation is directly proportional with general evaluation, so we can reject H015.

\section{Assignments: It was written in a clear way and what is required is declared obviously}

Hypothesis:

$\mathrm{H}_{16}$ : general evaluation of each tutor/course is independent from his/her evaluation in assignment clarity.

H1 16: general evaluation of each tutor/course depends on his/her evaluation in assignment clarity.

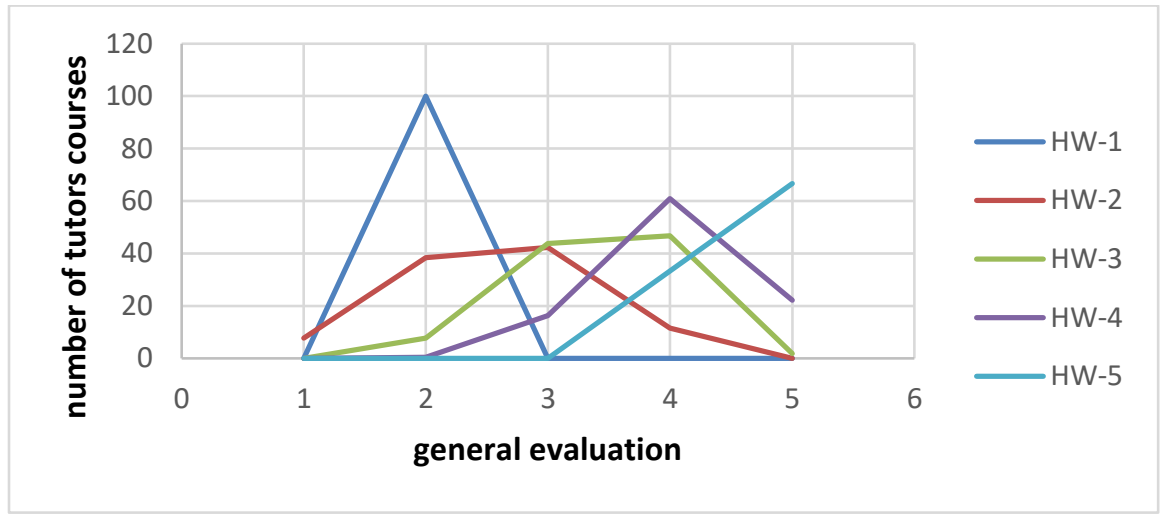

Fig (16-1) general evaluation \& assignment clarity

Results:

From Fig (16-1), we find that assignment clarity evaluation has no direct relation with general evaluation and we can't reject $\mathrm{H} 016$.

\section{Assignment help students to increase their understanding}

Hypothesis:

$\mathrm{HO}_{17}$ : general evaluation of each tutor/course is independent from his/her evaluation in assignment cooperation to course.

H117: general evaluation of each tutor/course depends on his/her evaluation in assignment cooperation to course.

This is equivalent in Stanford evaluation questionnaire to 5.3 in chapter 2.2. 


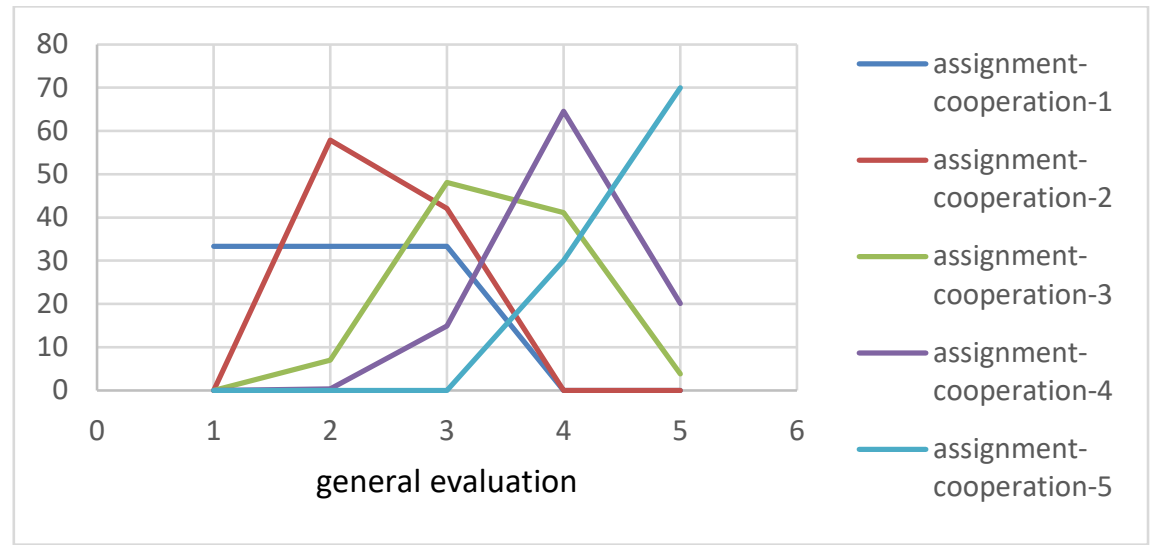

Fig (17-1) general evaluation \& assignment assistance

Results:

With ignoring marginal values (1 and 5), since the peak value of the general evaluation equals assignment cooperation to course evaluation and the biggest number of tutorcourse has identical values of general evaluation and assignment assistance factor evaluation (the peak of assignment-cooperation-2 graph confronts a SET value equals 2 and assignment-cooperation-3 graph confronts a SET value equals 3 and so on), we find that assignment cooperation to course evaluation is directly proportional with general evaluation_so we can reject $\mathbf{H 0 1 7}$. On the other hand, there is little abnormality in the assignment-cooperation-3 graph.

\section{Evaluation criteria:}

Grading policy was explained well for assignments and exams

Hypothesis:

$\mathrm{H} 0$ 18: general evaluation of each tutor/course is independent from his/her evaluation in declaration of evaluation criteria

$\mathrm{H} 1_{18}$ : general evaluation of each tutor/course depends on his/her evaluation in declaration of evaluation criteria

This is equivalent in Stanford evaluation questionnaire to 5.4 in chapter 2.2.

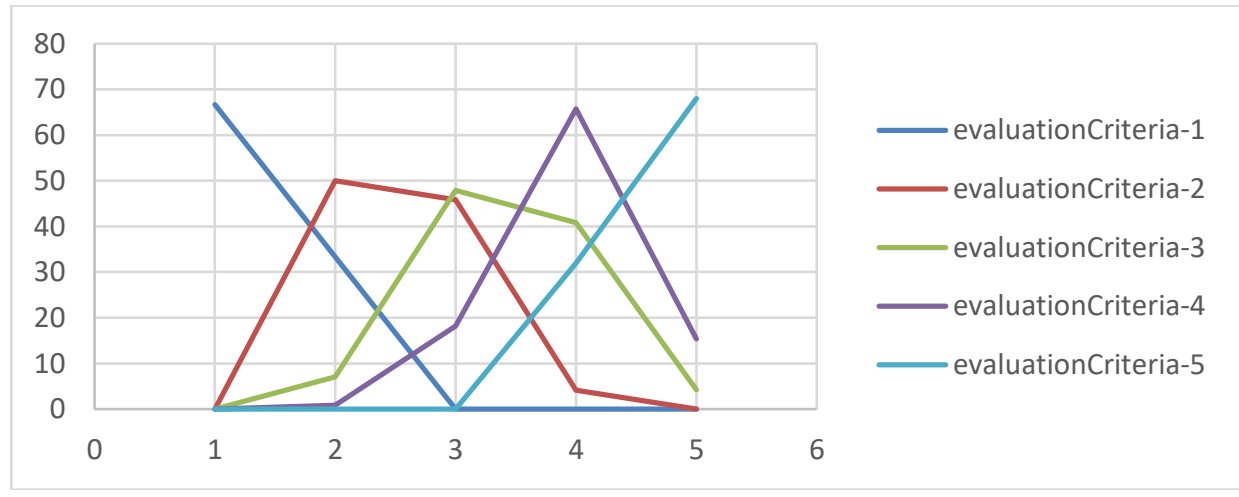

Fig (18-1) general evaluation \& evaluation criteria

Results:

With ignoring marginal values $(1,5)$, since the peak value of the general evaluation equals declaration of evaluation criteria evaluation and the biggest number of tutor-course has 
identical values of general evaluation and evaluation criteria factor (the peak of evaluationCriteria-2 graph confronts a SET value equals 2 and evaluationCriteria-3 graph confronts a SET value equals 3 and so on), we find that declaration of evaluation criteria evaluation is directly proportional with general evaluation so we can reject $\mathrm{H}_{18}$.

From all figures: We can find that relations were clearer in some factors than the others. This may indicate how much each factor influences the total evaluation. In our study we concentrated whether each factor affect the SET or not, so we didn't use these previous results but we may use them later in other researches.

\subsection{SVU evaluation questionnaire}

This will be the questionnaire after eliminating general evaluation question and questions that was proved to be useless and did not affect SET.

Through following the course on Moodle you found that:

1- Course organization was clear detailed and with sufficient resources

Through following synchronous and recorded sessions you found that:

2- In each session, objective was explained well

3- Ideas and concepts were clear and related to each other

4- Sessions were supported with sufficient examples

5- Discussion method was applied in synchronous sessions

6- Response to students' questions was clear and sufficient

7- Commitment in online sessions timing

8- Sessions were uploaded on time without delay

Through doing assignments you found that

11-It was written in a clear way and what is required is declared obviously

12- It helps you to increase your understanding

13- Grading policy was explained well for assignments

Through dealing with the tutor you found that

14 - Response to students' questions outside sessions and in different ways (email- Moodle - social network - FB ...etc)

15- Tutor knowledge of technology and using virtual learning tools

\section{CONCLUSION}

In this article, we customized SET questionnaire used in traditional learning to be convenient with virtual learning after studying affected factors.

Virtual learning environment doesn't depend completely on online sessions, but it depends also on student's self-studying with the assistance of well-organized content, and that produces new factors that affect the evaluation process such as how much the tutor has organized well the course content in the used LMS system (Moodle).

Our study shows that as much as the tutor cares about his/her online sessions, he/she will gain a higher SET evaluation, this care comes in ways of being committed to the sessions timings, being clear in determining and delivering its objective and ideas, supporting the ideas with suitable examples, and finally being effective in interacting with the students and responding to their issues and questions. 
Generally, our results prove that many traditional factors such as: number of attendees, tutor gender, tutor age, tutor specialty, have no effect on students' evaluation in virtual learning environment, as there is no face to face interaction between students and tutors. In a self-learning systems like that are used in SVU, where all online sessions are recorded and available for students at any time, the number of attendees doesn't affect tutors' evaluation. Also it doesn't matter if the tutors inform their students about sessions cancellation or not, while they will provide the recording or repeating it later.

While new introduced factors affect SET positively such as: course success rate, learning management system organization in a manner that shows explicitly it's subjects- activitiesassignments- instructions and grading policies, interactivity during on-line sessions, tutor's commitment, clarity of evaluation criteria in assignments and exams grading...etc.

We find also that we should exclude general evaluation question and factors that do not affect student evaluation of teaching in virtual learning from the questionnaire.

In addition, we find that it's enough to make the questionnaire once per semester, as the questions are comprehensive to activities during the whole semester.

To ensure the credibility of our results, we took samples of (sessions recordings assignments - course content pages in learning management system) for some low SET evaluated tutors, and we checked all the studied factors manually. It was proved that the majority of tutors with low SET evaluation have low interactivity in their sessions and bad organized pages in learning management system.

SET is a part of quality assurance process in virtual learning that will be applied at SVU. After exploring student evaluation of teaching, our next step is studying other types of tutor evaluation such as evaluation of tutors by SVU administration and tutor to tutor evaluation.... etc.

\section{REFERENCES}

Alauddin, Mohammad (August 2015), Does the student evaluation of teaching instrument Really measure instructors' teaching effectiveness? An econometric analysis of Students' perceptions in economics courses

Bachen, C. M., McLoughlin, M. M., \& Garcia, S. S. (1999). Assessing the role of gender in college students' evaluations of faculty. Communication Education, 48(3), 193-210. https://doi.org/10.1080/03634529909379169

Badri, M. A., Abdulla, M., Kamali, M. A., \& Dodeen, H. (2006). Identifying potential biasing variables in student evaluation of teaching in a newly accredited business program in the UAE. International Journal of Educational Management, 20(1), 43- 59. https://doi.org/10.1108/09513540610639585

Bonitz, Verena Sylvia (2011) Student evaluation of teaching: Individual differences And bias effects

Clifford Nowell, Lewis R. Gale and Bruce Handley John B. Goddard, (July 2010),Assessing faculty performance using student evaluations of teaching in an uncontrolled setting 
De Carvalho Eduardo, Bruno de Paula Rocha,(2011), Factors Affecting the Student Evaluation of Teaching Scores: Evidence from Panel Data Estimation

Drago, W. \&Peltier, J. (2004). The Effects of Class Size on Effectiveness of Online Courses. Management Research News

Liu Ou Lydia (JANUARY 2012), Student Evaluation of Instruction: In the New Paradigm of Distance Education.

Herbert W. Marsh and Lawrence A. Roche University of Western Sydney, Macarthur ,(Nov 1997), Making Students' Evaluations of Teaching Effectiveness Effective The Critical Issues of Validity, Bias, and Utility.

James E. Miller, Ph.D. Harding University. (2007).Student Evaluations of Teaching: Perceived Merits and Disadvantages, and Suggestions for Improving the Assessment Method

James S. Pounder (2007). Is student evaluation of teaching worthwhile? An analytical framework for answering the question.

Palmer, Stuart 2011, (2011), An institutional study of the influence of 'onlineness' on student evaluation of teaching in a dual mode Australian university.

STANFORD UNIVERSITY NEWSLETTER ON TEACHING (FALL 1997) Using Student Evaluations to Improve Teaching 